ISSN: 0514-7336

DOI: https://doi.org/10.14201/zephyrus201678131150

\title{
HUCHAS CERÁMICAS DE ÉPOCA ROMANA. A PROPÓSITO DEL HALLAZGO DE UNA TUMBA EN AUGUSTA EMERITA (MÉRIDA, BADAJOZ)
}

\section{Roman money boxes in pottery. A discovery in a grave from Augusta Emerita (Mérida, Badajoz)}

\author{
Ana María Bejarano Osorio* y Macarena Bustamante Álvarez** \\ * Consorcio de la Ciudad Monumental, Histórica, Artística y Arqueológica de Mérida. Cl Santa Julia, 5. 06800 \\ Mérida.Correo-e: ana@consorciomerida.org \\ ** Dpto. de Historia y Teoría del Arte. Facultad de Filosofía y Letras-UAM. Cl Francisco Tomás y Valiente, n. 1. \\ 28049 Madrid. Correo-e: macarena.bustamante@uam.es
}

Recepción: 18/04/2016; Revisión: 16/07/2016; Aceptación: 9/09/2016

\begin{abstract}
Resumen: En este trabajo se analiza un ajuar funerario hallado en un enterramiento femenino realizado en Augusta Emerita (Mérida, Badajoz). La localización de esta cremación se ha producido durante una reciente intervención en una de las áreas funerarias más importantes de la ciudad, la que en la zona sur bordeaba la antigua colonia romana.

Además del interés que ofrece la tumba en sí, es relevante la aparición de un depósito funerario inusual. Por ello, presentamos en primer lugar un panorama general que permite valorar la utilización continuada de toda esta área funeraria. Nuestro trabajo también se ha centrado en el estudio detallado del propio depósito funerario. A continuación analizamos una hucha que formaba parte de este ajuar. Puesto que se trata de una rara avis en el menaje cerámico hispano, a propósito de este hallazgo se hace una reflexión tipológica y funcional de dichas piezas en el Imperio Romano.

Palabras clave: Lusitania; enterramiento femenino; cremación; ajuar funerario; alcancía.

AвSTRACT: In this work, a funerary deposit found in a female burial in Augusta Emerita (Mérida, Badajoz) is analyzed. The location of this cremation has occurred during a recent excavation in one of the most important funerary areas of the city, in the southern area bordering the ancient Roman colony.

Besides the interest offered by the tomb itself, it is important the appearance of an unusual funerary deposit. Therefore, we first pressent an overview that allows us to assess the continued use of all this funerary area. Our work has also focused on the detailed study of the funeral grave itself. We discuss a money box that was part of the deposit. Since it is a rara avis in the Spanish ceramic utensils, apropos of this finding, a typological and functional reflection of such parts in the Roman Empire is done.

Key words: Lusitania; female grave; cremation; funerary deposit; money box.
\end{abstract}

\section{Introducción}

En una intervención llevada a cabo en los últimos ańos en la antigua ciudad hispanorromana de
Augusta Emerita se ha localizado una tumba de incineración inédita hasta la fecha. Esta ha aportado interesantes datos, no solo en lo referido al ritual mortuorio asociado, sino de igual modo en relación 
al depósito funerario exhumado que permite apuntar -junto a un estudio antropológico de los restos óseos- que estamos ante una difunta adulta. Entre los objetos recuperados, además de piezas metálicas, de eboraria e incluso madreperla, sobresalía una hucha en cerámica hecha ex profeso para almacenar dinero.

Además de un profundo análisis sobre la tumba y su contexto espacial, centraremos gran parte de la intervención en la autopsia de la alcancía, ya que, en una primera toma de contacto con otros contextos de similar entidad, hemos comprobado que la aparición de este tipo de recipientes no es muy común en suelo hispano. Por ello, decidimos realizar el estudio que ahora presentamos y que se centra, fundamentalmente, en el análisis tipológico, funcional y cronológico de este tipo de recipientes. También nos hemos acercado a su problemática en otros puntos del Imperio con el fin de intentar trazar una posible evolución cronológica y tipológica de estos recipientes.

\section{La necrópolis sur de Augusta Emerita}

El enterramiento que valoramos se localizó en el área sur de la ciudad de Mérida, concretamente en la c/ Barcelona ${ }^{1}$. Su hallazgo fue el resultado de una intervención puntual en una zona arqueológicamente bien documentada ya desde hace tiempo y cuyo estudio se ha reactivado gracias al desarrollo urbanístico de los últimos años en esta zona de Mérida.

Atendiendo a los datos aportados por estas excavaciones, se puede establecer una clara secuencia cronológico-espacial, que tiene sus inicios con una temprana ocupación situada en las márgenes del río, testimoniada por la presencia de diversos útiles líticos y datada en el Paleolítico Inferior y Medio (Alba y Méndez, 2005: 377-380, figs. 4-6).

La siguiente etapa ocupacional se relaciona con el período romano, momento de fundación y desarrollo de la colonia. Es en esta fase temprana en la que se

1 Excavación realizada durante los meses de marzo-mayo del año 2015.

(C) Universidad de Salamanca configura la ciudad con todos sus elementos cuando se articula este espacio extramuros que quedaría definido por dos elementos vertebradores: por una parte, la vía Camino 4 (Sánchez Barrero, 2010: 143150, fig. 61) que, con salida en la puerta sur, en eje con el cardo maximo de la ciudad, enlazaba la ciudad con la provincia Baetica, y, por otra parte, el límite natural impuesto por la presencia del río Anas en su margen derecha (Fig. 1).

Las intervenciones efectuadas en esta extensa área nos han permitido reconocer un complejo entramado de caminos secundarios que, partiendo de la vía principal, articulaban el territorio, generando espacios que fueron ocupados con actividades diversas. Las ocupaciones de estas parcelas fueron básicamente funerarias, industriales $\mathrm{y}$, en menor medida, domésticas.

Comenzando por las áreas industriales, estas se sitúan en la proximidad al cauce del río, lugar idóneo para la obtención tanto de la materia prima como del agua precisa en el proceso de elaboración. Estas áreas industriales se vinculan con una secuencia de hornos y barreros (Méndez y Alba, 2004: 307-332; Alba y Méndez, 2005: 375-409; Alba, 2005: 343-374), a los que sumar piletas de decantación y pozos de agua (Alba y Méndez, 2005: 384-386, figs. 11-12). Todos estos elementos nos hablan de la presencia de figlinae destinadas a la confección tanto de vajilla doméstica -cuencos, platos, botellas, etc.-, como del material latericio necesario para la construcción de la incipiente ciudad. La cronología aportada por los materiales hallados sitúa el inicio de la producción de estos hornos en el s. I, con un desarrollo fundamentalmente en el s. II d. C. (Méndez y Alba, 2004: 317-320).

Una de las estructuras de combustión se ha podido identificar, de forma parcial, en el solar objeto de nuestra intervención. Se trataría de un horno cuya planta, en función de lo escaso documentado, parece corresponder con el modelo rectangular, Le $\mathrm{Ny}$ tipo II-E, al que se asociaba un área de vertido de material cerámico defectuoso. Este vertedero amortizaba un enterramiento anterior, datado en función de los materiales en el último tercio del s. I d. C.

Zephyrus, LXXVIII, julio-diciembre 2016, 131-150 


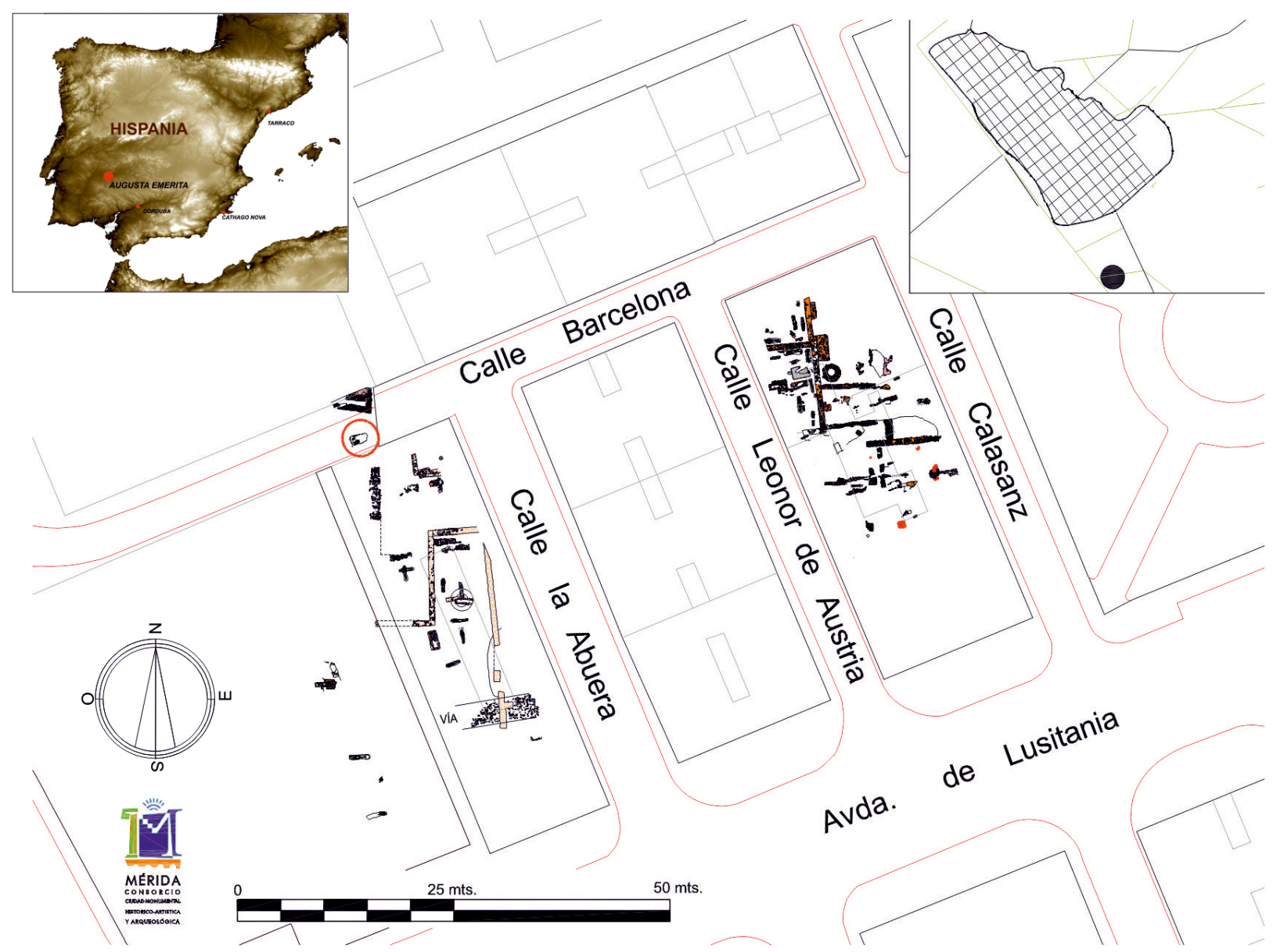

Fig. 1. Plano de ubicación de la sepultura en el entramado romano de Mérida (Dpto. Documentación del Consorcio Ciudad Monumental de Mérida).

Un análisis espacial de la zona nos permite ver la convivencia de estos talleres con otros espacios de funcionalidad totalmente distinta. En este sentido hemos de hablar de la ocupación doméstica de la zona de la que se conservan escasos testimonios que, no obstante, nos hablan de una temprana edilicia vinculada a casas extramuros (Méndez, 2006: 357382; Nodar, 2001: 267-283).

Es la villa suburbana situada en el actual solar del 'Centro Universitario de Mérida' la que nos aporta mayor información sobre estas edificaciones, construidas en un momento temprano del s. I para ser abandonadas a finales del mismo. La edificación de esta vivienda se ha vinculado con las cercanas instalaciones industriales planteándose, a modo de hipótesis, una casa que formara parte de un fundus, destinado a la producción y abastecimiento de materiales a la ciudad durante sus principales años de demanda, de ahí su temprano abandono (Nodar, 2001: 277-278), misma motivación que tal vez debamos asignar a la construcción de otra casa en el entorno próximo de los hornos y barreros (Méndez, 2006: 378-379).

Sin embargo, tal y como es habitual en todo enclave romano que sigue los parámetros establecidos en las legislaciones vigentes (Abascal, 1991: 220227), son las áreas funerarias las que muestran un mayor desarrollo. Concretamente hablamos del registro de un importante y extenso espacio sepulcral que se ubica tanto a un lado como otro de la vía principal, y que ocupa los espacios intermedios regulados por el citado entramado de vías secundarias. 
Centrándonos en la zona que nos ocupa, podemos ver cómo desde los inicios de la colonia se van erigiendo amplios recintos, así como mausoleos de mayor o menor entidad, en torno a los cuales se disponen enterramientos individuales que nos hablan de una ocupación densa y continuada. Destaca en la zona la presencia de un potente muro identificado en más de $112 \mathrm{~m}$ de longitud, provisto de contrafuertes (Méndez, 2006: 380), que establece la división entre el área a ocupar con enterramientos y la vía principal.

Estas edificaciones se nos muestran como un paisaje continuo que flanquea ambos lados de la vía principal hacia la que se orientan. Pero lo más reseñable es sin duda la presencia de los amplios recintos funerarios que, algo más alejados de la ciudad y siempre en función de la vía y el entramado urbano, desarrollan sus plantas de grandes dimensiones mostrando una alta ocupación continuada en el tiempo. Los primeros edificios registrados datan de mediados del s. I d. C. y corresponden a recintos a cielo abierto con enterramientos, indistintamente, de incineración o inhumación y de la más variada tipología constructiva. Estas edificaciones se desarrollan siguiendo los parámetros orquestados por la centuriación urbana que servía no solo como eje en el trazado de las vías secundarias, sino como director en la disposición de las edificaciones funerarias reconocidas (Bejarano et al., 2015: 190-193, lám. 1; Sánchez Barrero, 2010: 152, fig. 101). Asociados a los mismos, nos encontramos con pozos, destinados a la obtención de agua para la celebración de los rituales y abluciones funerarias, ampliamente atestiguados en el solar emeritense (Márquez, 2005: 293-297; Alba, 2005: 333-335).

La ocupación de los terrenos, en lo que a nuestra área se refiere, se resuelve como un proceso continuado en el tiempo, con una sucesión de sepulturas en una "secuencia discontinua" (Márquez, 2005: 297), hasta el s. III d. C., momento en el cual se localizan sepulturas básicamente de inhumación provistas de depósitos materiales, que se superponen espacialmente a enterramientos previos.

Tras un hiato ocupacional de esta área, la siguiente etapa se fecha en época islámica, con el desarrollo de una importante maqbara datada entre los ss. VIII y XI con pervivencia hasta el Califato (Alba, 2011: 21-26), y que se extiende alejada de los límites de la ciudad, por toda la margen derecha del río, con enterramientos que imitan en algunos casos las sepulturas visigodas, peo que paulatinamente se van ciñendo al ritual tradicional, es decir, una posición decúbito lateral, orientada hacia La Meca, y carentes de depósito material.

Esta misma secuencia la hemos podido registrar en el solar que nos ocupa, donde a la ocupación industrial le sucede la presencia de enterramientos de época romana, un exiguo número de 7 en todo el solar, con dataciones que los sitúan entre mediados del s. I -1 incineración- y el bajoimperio -6 inhumaciones-. Con posterioridad, asistimos a un abandono de la zona que será reocupada por tumbas islámicas, 37 de un total de 44 que se ciñen a la etapa emiral-califal.

Espacialmente, en el área intervenida se aprecia una menor superposición ocupacional en referencia a lo documentado en los solares contiguos. Así, observamos cómo las tumbas islámicas se acumulan en lugares libres de enterramientos o estructuras precedentes, donde la roca natural, blanda y por lo tanto de fácil trabajo, aflora rápidamente en superficie. Es escaso el proceso de reocupación de terrenos ya empleados para otras estructuras de enterramiento, ceñido básicamente a las zonas más cercanas a los edificios (recintos y mausoleos) de las áreas colindantes. Dentro de los pocos casos de superposición registrados, uno de ellos es la tumba que nos ocupa, que se vio parcialmente afectada por una sepultura islámica posterior.

\section{Análisis de una sepultura de incineración excepcional}

Dentro de la amplia necrópolis intervenida, interesa particularmente una tumba por el ritual acogido y, sobre todo, por el depósito funerario que contuvo. Dentro de esta zona funeraria, mayoritariamente de inhumación, el único enterramiento que presenta ritual de incineración es el que ahora centra nuestra atención.

Esta sepultura se fecha, en función de los materiales, a mediados del s. I d. C. A pesar de ser la única 


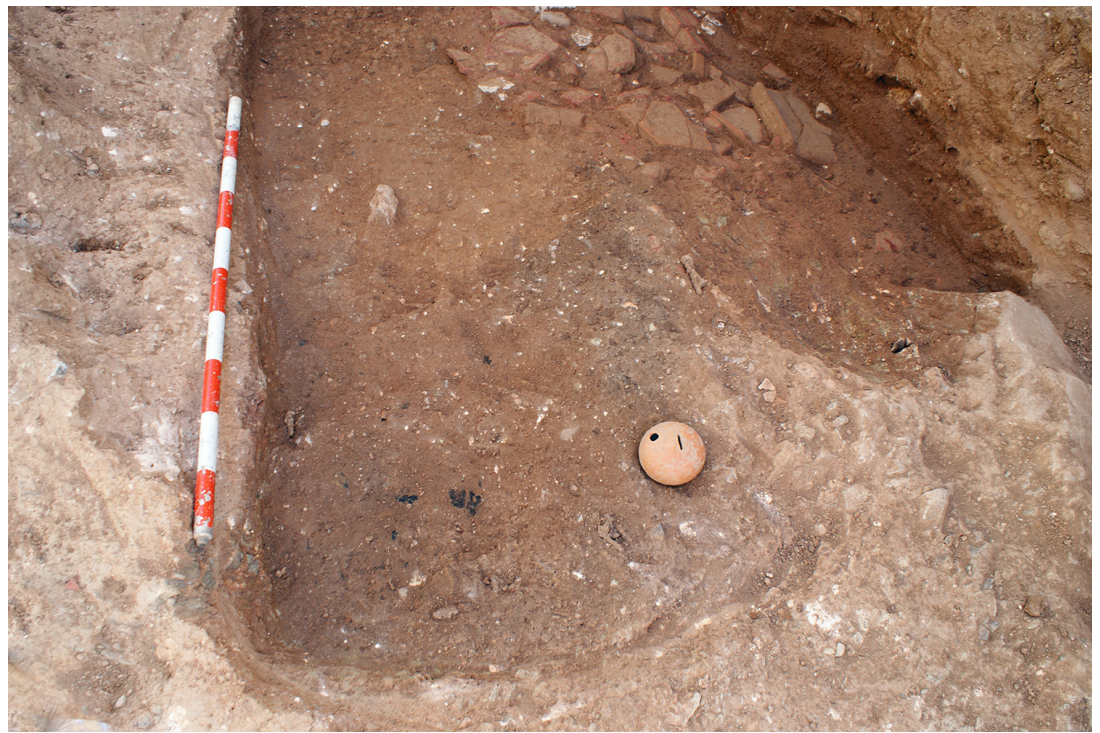

Fig. 2. Fotografía general de la sepultura.

A lo largo del perímetro interno de la incineración, acumulado preferentemente en los bordes de la fosa, se documentaron numerosos restos lígneos calcinados y clavos de hierro dispuestos básicamente a ambos lados y al NO -al SE estaba cortada-, lo que nos indicaría la presencia de un lectus o bien las parihuelas en las que se trasladaba el cadáver, común en este tipo de rituales (Vaquerizo, 2010: 24-31).

Los restos de la cremación se concentraban junto a la pared sur de la fosa. En este punto se localizó un túmulo donde

documentada de época altoimperial, sin embargo, no sería un elemento aislado sino que estaría en relación con los enterramientos de la misma época documentados en el solar cercano de la c/ Albuera o Leonor de Austria (Márquez, 2005; Alba, 2005) (Fig. 2).

La tumba, tipológicamente, se constituye como un bustum, sepultura en fosa simple que llegaba a los niveles de roca natural, con una planta tendente al rectángulo, de esquinas redondeadas. Aparecía parcialmente conservada ya que se vio afectada por un enterramiento posterior de época islámica que la cortaba en su parte suroriental.

Superficialmente la sepultura se identificaba por el delineado de trazo rojizo negruzco que marcaba la fosa, cristalización visual del proceso de purificación previo a la colocación de los restos de la cremación. Las paredes interiores aparecían totalmente termoalteradas por la acción del fuego.

Las dimensiones conservadas correspondían a una longitud de $1,36 \mathrm{~m}$, una anchura media de 75 $\mathrm{cm}$, una profundidad de $10 \mathrm{~cm}$ y una orientación SE-NO.

La totalidad del enterramiento estaba amortizada por un relleno de tierra que no aportaba material alguno y del que sobresalía la parte superior de una pieza cerámica, la hucha, que se asocia al depósito material. se acumulaban los trozos de leños calcinados a los que se asociaban fragmentos óseos igualmente cremados. Entre las partes identificadas asociadas al esqueleto del difunto se reconocen elementos corticales de la falange distal, el húmero, el cubito y el radio. Un macroanálisis del grosor y la compactación de los mismos viene a confirmar la edad adulta del difunto; sin embargo, debido al estado de conservación de los restos cremados no se puede determinar el sexo, aunque se puede intuir como fémina debido al ajuar que lo acompaña.

Esta incineración, datada en el s. I d. C., tanto por el ritual al que se adscribe, una cremación, como por su tipología, carece de interés ya que forma parte de la multiplicidad de enterramientos de incineración que a lo largo del s. I d. C. componían el paisaje funerario de las áreas extramuros de la ciudad de Augusta Emerita, ampliamente documentado a lo largo de estos ańos de intensa actividad arqueológica (Márquez, 2008: 443-469; Bejarano, 2002: 232-233, Molano y Alvarado, 1994: 333-335).

La singularidad de la misma, y lo que motiva su estudio, radica en parte del depósito material hallado en su interior con piezas de rara aparición en suelo emeritense. Nos referimos, por una parte, a la presencia de la hucha, la primera de esta tipología registrada en la ciudad y con escasos hallazgos 


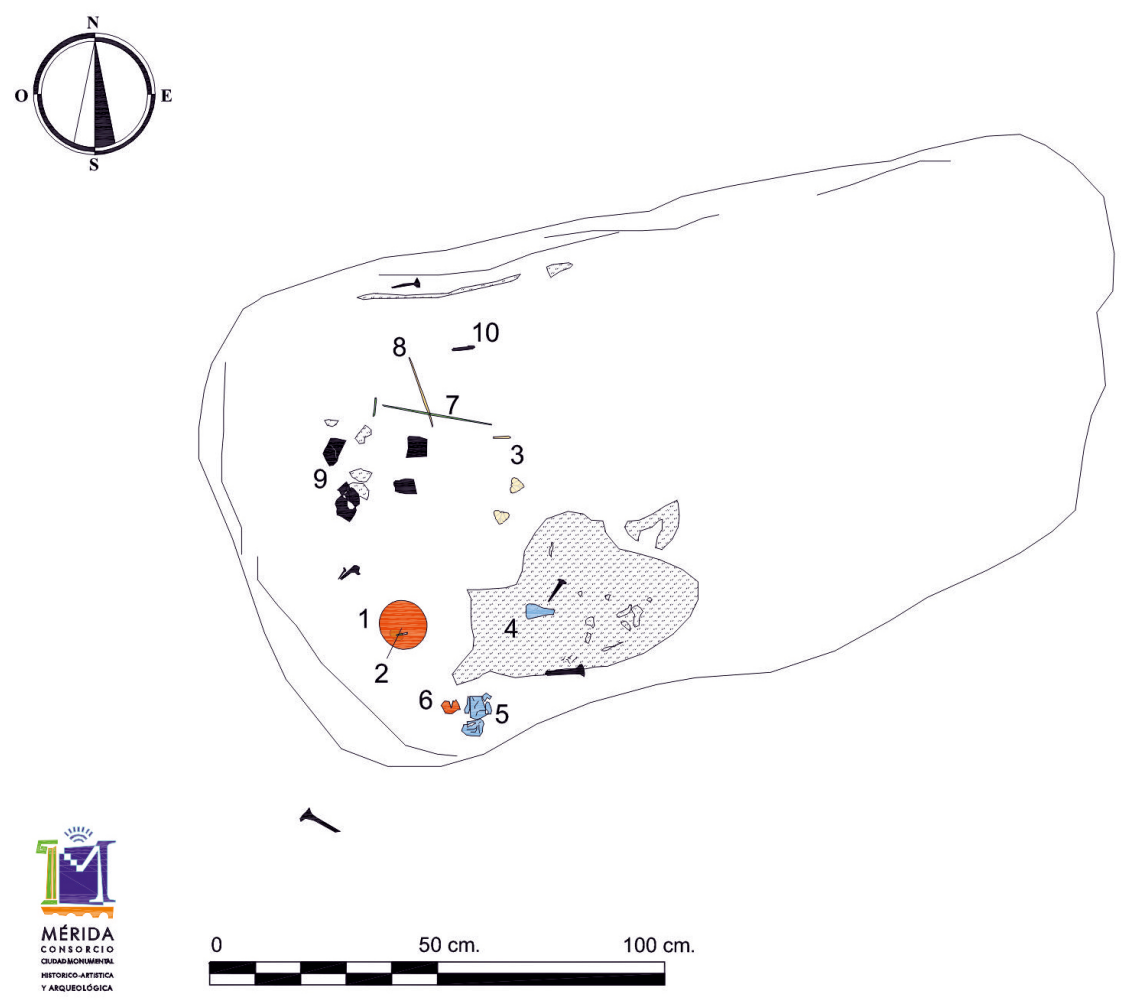

Fig. 3. Planta de la sepultura y ubicación del depósito funerario en su interior (Dpto. Documentación del Consorcio Ciudad Monumental de Mérida). una hucha (Fig. 5), bajo la cual estaba situada una moneda de bronce frustra por encontrarse calcinada. Junto a esta se había colocado un cuenco fragmentado de paredes finas emeritenses, con decoración de lúnulas a barbotina del tipo Mayet XLIII (Fig. 6, n. ${ }^{\circ}$ 179/12) (Mayet, 1975: 98-99, pl. LXIII; Bustamante, 2014: 1467-1469). En las proximidades de estos objetos cerámicos se agrupaban las piezas de vidrio, concretamente tres objetos fragmentados; el primero de ellos, incompleto, es un ungüentario de color azulado Isings $82 \mathrm{~b} 1$ (1957: 97-99) (Fig. 6, n.o 179/9); el segundo correspondería a múltiples fragen Hispania, y, por otra parte, la existencia de dos adornos de nácar, de los cuales hay varios ejemplos procedentes, al igual que los nuestros, de las áreas funerarias emeritenses.

Traemos a colación el proceso de intervención, ya que no es frecuente su análisis en trabajos de esta magnitud. Este conjunto material se hallaba amortizado por un estrato terroso (Fig. 3). Una vez retirado este sustrato se comenzaron a percibir los materiales que conformaban el depósito funerario que se asentaba sobre la capa de cenizas y carbones, resultado de la cremación. Estamos hablando de un depósito secundario, es decir, colocado una vez que se habían recogido los vestigios de la incineración, objetos que acompañaban al difunto en su vida al más allá (Fig. 4), piezas representativas o valiosas para él o sus familiares (Bejarano, 2015: 131).

Dicho conjunto se componía de varios elementos agrupados y distribuidos intencionadamente por la sepultura. Así, en la zona so se localizó

(C) Universidad de Salamanca mentos de una botella de tonalidad verde-azulada del tipo Isings 57 (1957: 76-77), y, finalmente, el tercero es un cuenco hemisférico de vidrio melado con irisaciones doradas Isings 8 (1957: 36-37).

En el extremo opuesto se habían dispuesto dos acus crinales en hueso, una de ellas muy degradada y fragmentada, así como un removedor, una varilla fina de bronce carente de remate al estar fragmentada en uno de sus extremos (Fig. 6, n. ${ }^{\text {os }}$ 179/4, 6, 12 y 17).

En el centro de la fosa documentamos varias piezas de una caja de la que únicamente se han conservado sus elementos metálicos (Fig. 6, n. ${ }^{\circ}$ 179/11). Concretamente, nos referimos a las cantoneras de hierro, provistas de orificios de anclaje y varias tachuelas de bronce. Esto nos induce a pensar que se tratara de una caja con alma de madera y remaches metálicos decorativos/funcionales en las esquinas que, posiblemente, sean los restos de una caja de maquillaje tan común en el tocador femenino de la época.

Zephyrus, LXXVIII, julio-diciembre 2016, 131-150 


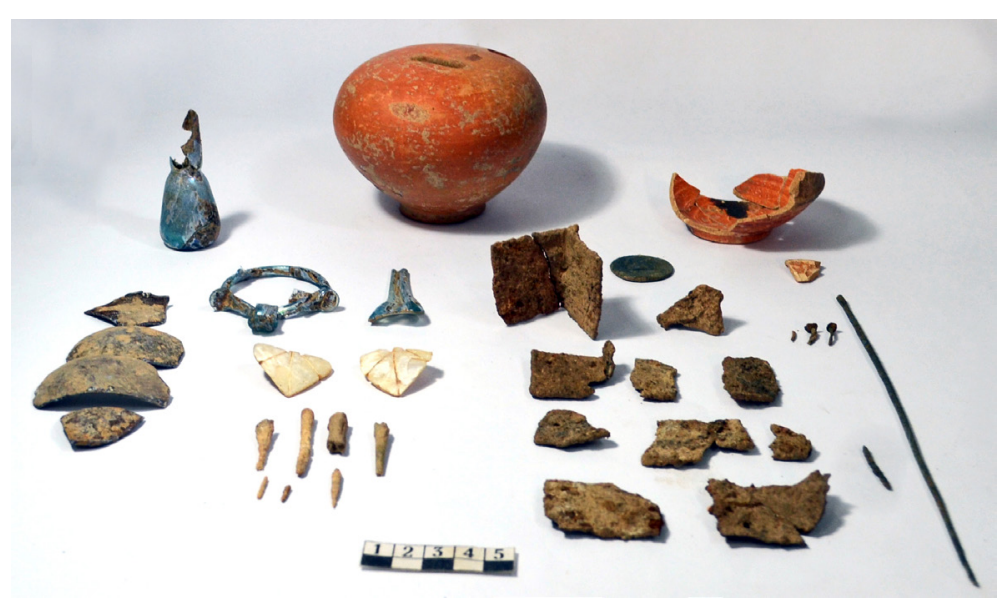

Fig. 4. Depósito funerario de la sepultura (lám. de materiales 3512/179; Dpto. Documentación del Consorcio Ciudad Monumental de Mérida).
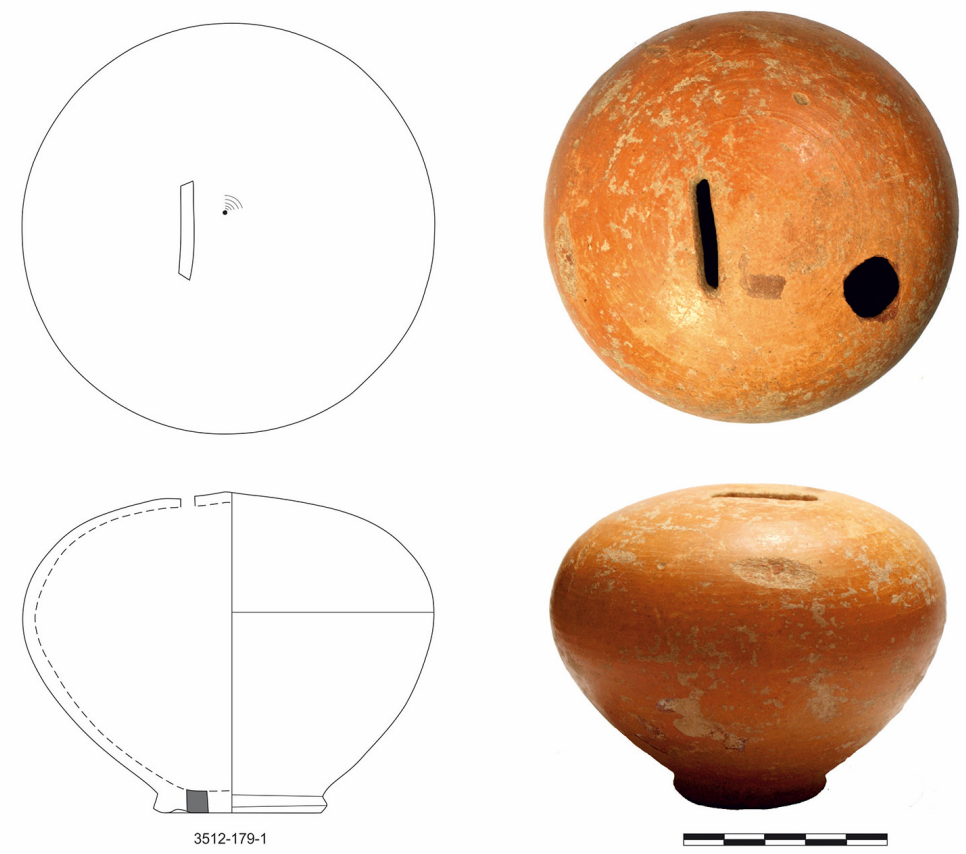

FIG. 5. Hucha cerámica localizada como parte del depósito funerario (Dibujo: Dpto. Documentación del Consorcio Ciudad Monumental de Mérida).

y $0,2 \mathrm{~cm}$ de grosor. La representación de la hoja aparece muy detallada en su haz, donde se marcan los nervios tanto radiales como el central, así como la base que se une al peciolo. Responden a hojas de forma cordada, con el margen crenado. La parte posterior de las hojas es lisa. En la parte superior, coincidente con el peciolo, se dejó en reserva un saliente de morfología rectangular sobre el que se practicaron dos orificios paralelos desde un plano vertical. Una autopsia pormenorizada de la pieza nos permite observar cómo fue manufacturada. Concretamente, este objeto presenta una curvatura propia de la materia prima que ha sido aprovechada para dar mayor realismo a la pieza. El plano de trabajo en el reverso es vertical, como se observa en las trazas que quedan del punzón romo usado para su tallado. En la cara externa, sin embargo, el trabajo ha sido horizontal, a excepción de los orificios para que pueda pender que han sido desarrollados en un plano vertical. Las líneas de la nervatura se practicaron por medio de un buril fino y preciso, posiblemente calentado para facilitar la incisión. El contorno de la flor, tras haber sido cortado, fue limado para evitar cortes en su uso.

A falta de un análisis arqueozoológico, podemos decir que estamos ante un posible fragmento de Halliotis tuberculata $^{2}$. Esta especie es característica de zonas costeras, aunque el consumo de piezas procedentes de es-

Por último, y algo más abajo de esta caja, aparecían dos artículos de nácar, colocados uno al lado del otro (Fig. 7). Estas piezas corresponden a dos objetos con forma de hoja de vid. Se trata de dos piezas de pequeñas dimensiones: una tiene $2,7 \mathrm{~cm}$ de altura x 3,25 de anchura máxima y 0,2 de grosor y la otra 2,8 cm de altura x 2,9 de anchura máxima tos lugares ya ha sido atestiguado en la capital de Lusitania (Rodríguez Hidalgo et al., 2013). El alto componente de aragonito que presentan los restos

2 Agradecemos los datos de identificación a los Drs. Viera, Izquierdo y Courtois de Viçose (Grupo de Investigación en Acuicultura [GIA], IU-ECOAQUA, Univ. de Las Palmas de Gran Canarias). 
138 A. M. Bejarano y M. Bustamante / Huchas cerámicas de época romana. A propósito del hallazgo de una tumba...
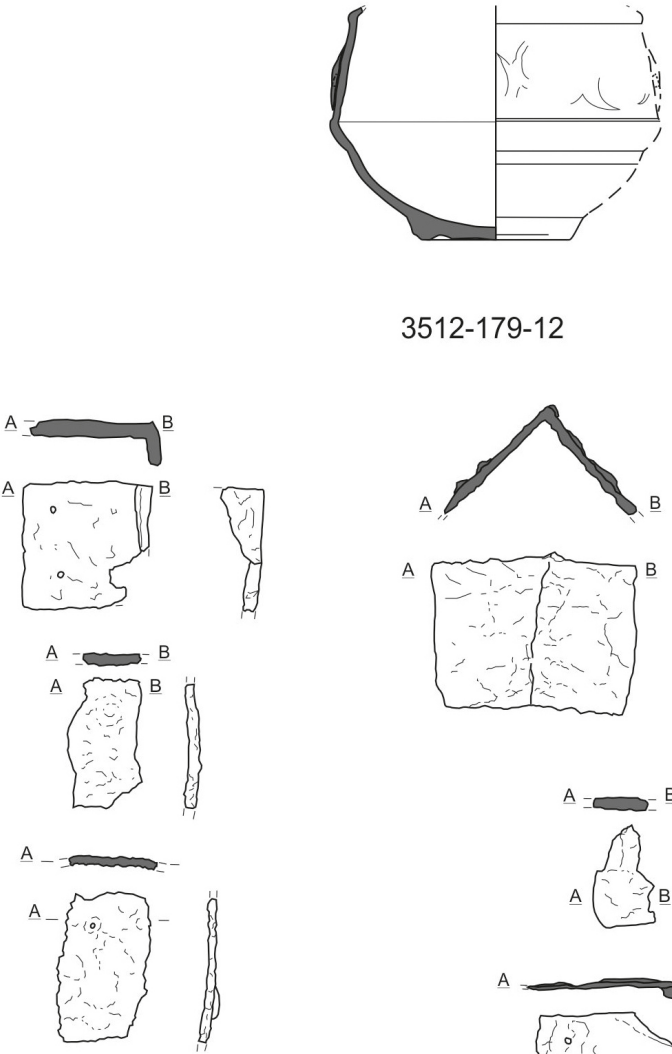

A
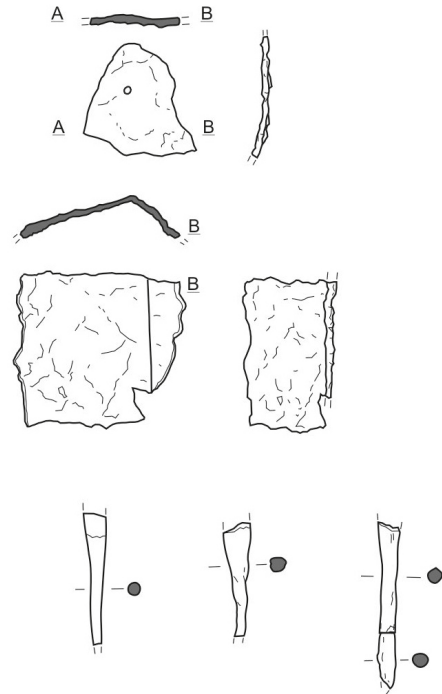

$3512-179-10$
3512-179-12
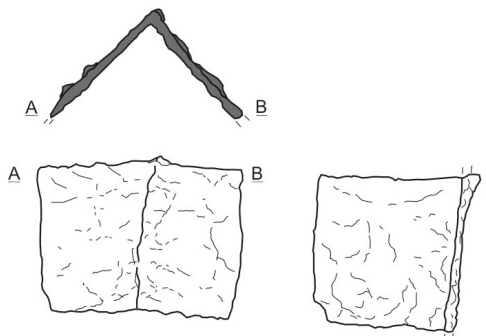

$\underline{A}=\underline{B}$
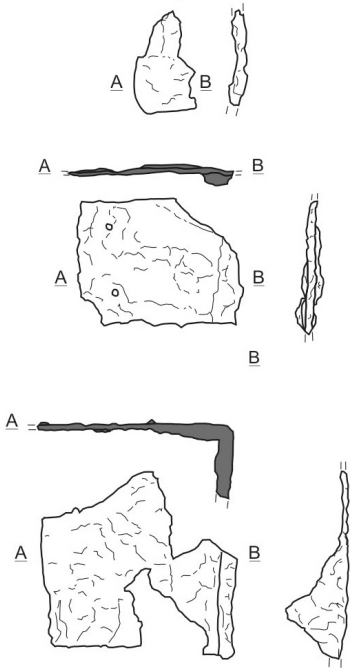

$3512-179-9$

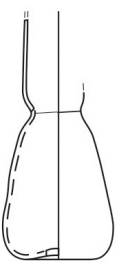

3512-179-11

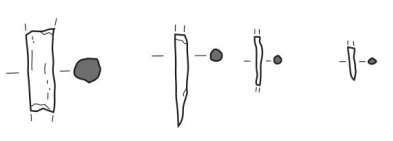

$3512-179-6$
$3512-179-3$
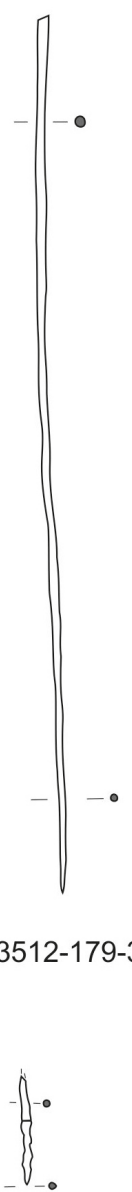

$3512-179-4$

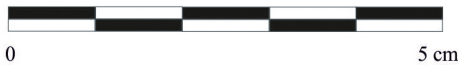

Fig. 6. Materiales localizados en el contexto de la hucha (lám. de materiales 3512/179; Dpto. Documentación del Consorcio Ciudad Monumental de Mérida). 


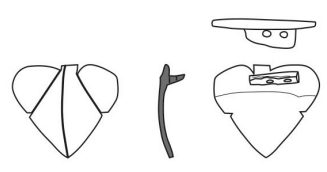

$3512-179-7$

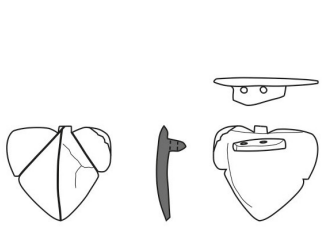

$3512-179-8$
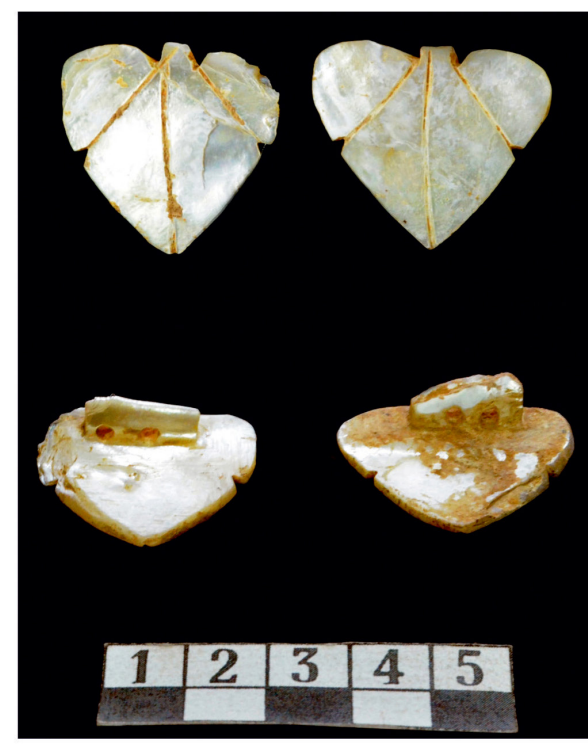

Fig. 7. Elementos de nácar reproduciendo la forma de hojas de vid.

de pasta vítrea, una de hueso y una de ámbar (Márquez y Pérez Maestro, 2005: 533-545). La segunda se localiza en el solar de la cl Almendralejo en una sepultura altoimperial en curso de estudio por sus excavadores.

Como hipótesis de la posible funcionalidad destinada a estas piezas creemos que serían adornos de la indumentaria femenina (Fig. 8). Bien como posibles colgantes que se penderían de un hilo desaparecido o, incluso, formando parte del calzado femenino como se saca de conclusión por paralelos en relivaria mayor. En este sentido

malacológicos, como es el nácar, le aporta una durabilidad extrema. Esta propiedad, bien conocida desde época prehistórica, fue también apreciada por los romanos y de ahí su consumo.

Estas hojas son dos elementos singulares realizados en nácar, un material que no resultaba muy abundante para la manufactura de objetos de la vida cotidiana, al menos en el registro que actualmente se tiene para Augusta Emerita ${ }^{3}$. No obstante, dentro del inventario material del Consorcio se documen$\tan$ otras cuatro hojas de vid, similares a las descritas, igualmente procedentes de depósitos funerarios, asociadas a otros elementos tanto de tocador como de ornamento. Dos de ellas han aparecido en una sepultura de incineración, un ustrinum, cuyo completo depósito funerario nos remite a una sepultura femenina fechada en la primera mitad del s. I d. C. (Chamizo, 2006: 24-25, fig. 12, y 33-34, figs. 29a-29b). Las otras dos piezas aparecen solas, en distintos solares de la ciudad, la primera de ellas se vincula a una inhumación en fosa simple y fue hallada a los pies del esqueleto junto a una cuenta

3 Son varias las piezas que, asociadas casi exclusivamente a depósitos de carácter funerario, se vinculan con adornos o elementos decorativos tales como un pendiente de la c/ Carderos o el aplique de una caja asociada a un pequeño mobiliario $(9008 / 00 / 18)$. el ornato de extremo de las sandalias tanto femeninas como masculinas es amplia en Roma. Además de presentar partes policromadas está documentado el uso de pequeños abalorios fabricados en metales preciosos, gemas y nácares (Daremberg-Saglio, 1904, s. v. "solea": 1389).

El interés de estas piezas radica en que son las únicas de este tipo. Frente a lo que se pudiera pensar, el uso del nácar o madreperla no estaba muy extendido en la Antigüedad. De hecho, su producción y comercialización parece que estuvo restringida a las clases más altas. Un hito histórico concreto, la entrada triunfal y ostentosa de Pompeyo con gran cantidad de piezas en este soporte en Roma, hizo que el consumo de las mismas quedase reducido a las clases más ricas. De hecho, ante la sobreexplotación de las mismas Julio César tuvo el control directo de las pesquerías destinadas a su explotación en el Mar Rojo e incluso impulsó leyes suntuarias que restringieron su uso a las clases más pudientes de la sociedad (Cariño y Monteforte, 2007: 98). Los escasos estudios hasta el momento llevados a cabo se centran tanto en las rutas comerciales de estos productos de lujo como en la epigrafía mayor de sus comerciantes, sobre todo, focalizados en Roma (Tassini, 1994: 690-692; Pérez González, 2014). De interés resulta la posible asociación de los 

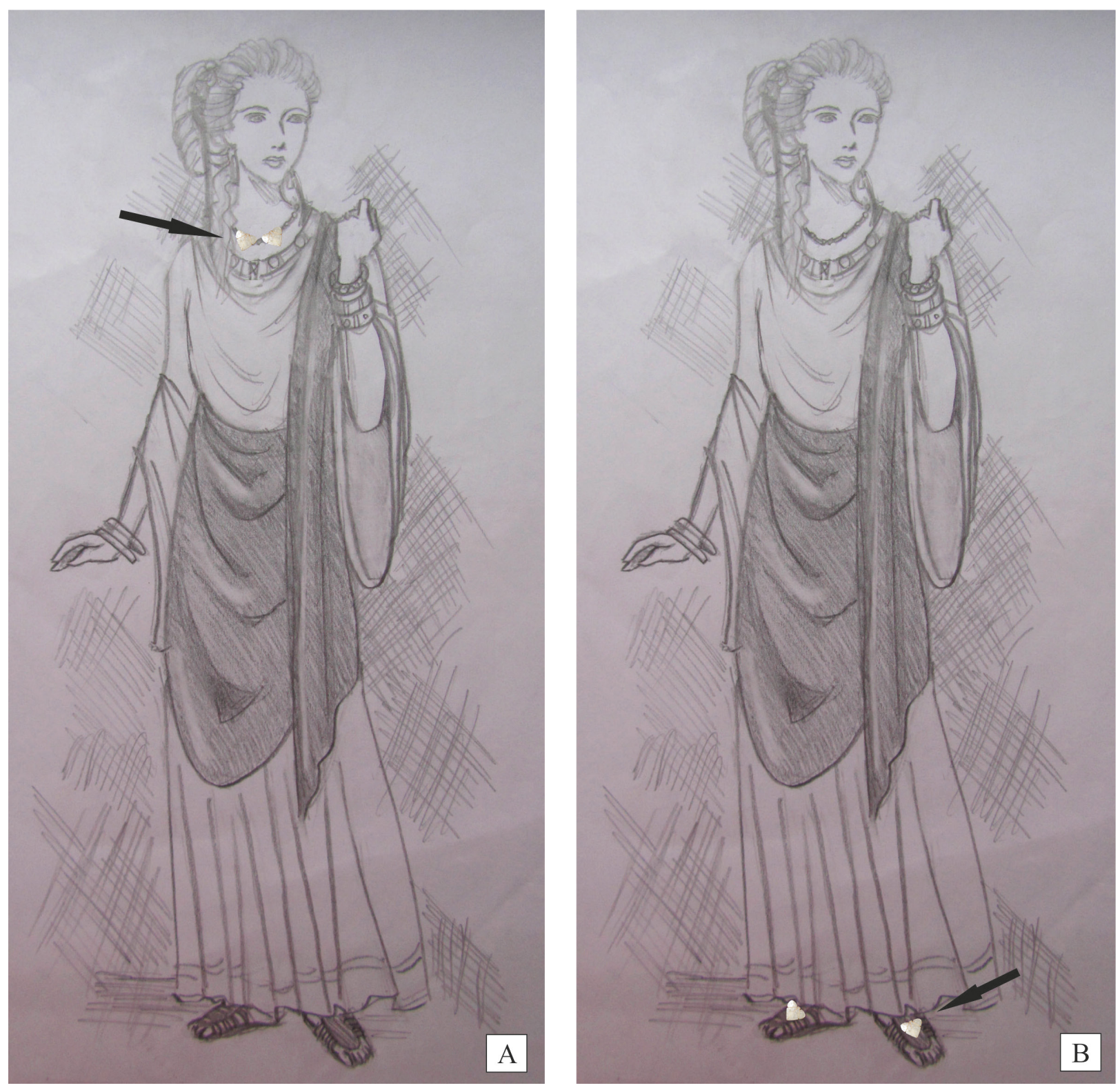

Fig. 8. Reconstrucción del posible uso de las piezas de nácar: A) como abalorios de collora y B) como decoración y para facilitar el atado de los zapatos (dibujo de G. Umpierrez).

comerciantes de estos productos a determinados cultos orientales, caso de Magna Mater y Attis. Hay que valorar que uno de los comerciantes dedicados a estos menesteres en la parte más occidental del Imperio se localiza precisamente en Augusta Emerita. Concretamente, en una inscripción funeraria conocida hace tiempo y deposicionalmente localizada en el castillo de las Navas del Marqués se alude a un tal Silvanus, de profesión margaritarius ${ }^{4}$. Esta documentación epigráfica, unida a la colección de piezas que hemos enumerado como procedentes

4 Reproducimos el texto a continuación: $D($ is $) M(a-$ nibus) s(acrum) / Silvanus Aris/taei fll(ius) an(norum) LXXX / margaritarius / Pr[ot]is lib(erta) et heres / patrono bene mer(enti) / [f(aciendum)] c(uravit) h(ic) s(itus) e(st) s(it) t(ibi) t(erra) l(evis) -CIL II, 496 e HEp. n.o 21515. 
de Mérida, hace que la ciudad, a pesar de su posicionamiento en el interior, se perfile como uno de los puntos que más datos nos aportan sobre el trabajo de este material.

\section{Análisis de la hucha cerámica}

Además de estas piezas, de relevante interés, ya nos hemos referido a la aparición de una hucha cerámica, cuya excepcionalidad obliga a realizar un estudio pormenorizado de la misma (Fig. 5). Su estado de conservación es notable. Se presenta completa y está manufacturada en barro cocido a torno, aunque también presenta aditamentos a mano, como su botón superior. Está realizada en arcilla de coloración muy anaranjada con desgrasantes micáceos y graníticos de granulometría media-baja. Se observa una delgada capa de engalba blanca preparatoria para recibir un fino engobe anaranjado cuya adherencia con el recipiente es muy débil, como se observa por el fuerte escamado que presenta superficialmente. Morfológicamente tiene una forma ovoide muy achatada. A priori podemos observar que su tipología es muy cercana a las ollas comunes, con pie anular definido con moldura inferior hispana. Sin embargo, la novedad se sitúa en la parte superior donde se realiza un brusco cierre semicircular no homogéneo culminado con una protuberancia superior a modo de botón muy esquematizado, meramente decorativo. Su fabricación presenta imperfecciones; por ejemplo, se aprecia un rehundido así como una muesca irregular en parte central del cuerpo, probablemente, producto de una manipulación precipitada cuando aún no se había secado. También la base, anular, está irregularmente traza$\mathrm{da}$ en los bordes.

Este análisis nos ha permitido comprobar cómo su manufactura no responde a un proyecto planificado sino más bien a un acto puntual; de ahí su tremendo parecido con las ollas locales.

Tiene una altura de $8 \mathrm{~cm}$, un diámetro máximo de $10,1 \mathrm{~cm}$ y un tamaño de base de $4,2 \mathrm{~cm}$. La ranura de inserción del monetario se sitúa en la parte superior. Es un corte realizado previamente al proceso tanto de cocción como de engobe de la pieza,

(C) Universidad de Salamanca ejecutado en sección trapezoidal. La ranura mide $2,5 \mathrm{~cm}$ de longitud al interior y $2,7 \mathrm{~cm}$ al exterior $\mathrm{y}$ tiene una anchura de $0,4 \mathrm{~cm}$.

La identificación de este objeto con una hucha es más que evidente, a pesar de que en su interior solo se halló la tierra que se filtró por la ranura y no se encontró ninguna moneda. Descartamos cualquier asociación con la moneda hallada bajo este recipiente debido a que su diámetro impide que esta se hubiera podido insertar en su interior.

El estudio de estas piezas no ha estado exento de debate empezando incluso por algo tan elemental como su propia nomenclatura. Así, el concepto hucha es un término derivado del latín medieval hutica (arca), palabra que aparece a finales del s. XII procedente del francés ${ }^{5}$. En España se empleaba para estos contenedores destinados al ahorro la palabra árabe alcancía, que aún persiste en nuestro vocabulario aun cuando está cayendo en desuso. No obstante, anterior a estos vocablos, no se conoce en latín clásico ni en las fuentes ningún término concreto para estos objetos que se designaron genéricamente como loculus, vocablo que parece ser el más adecuado y comúnmente aceptado a la hora de nominar estos objetos (Thédenat, 1904: 1292-1293).

Una vez definida su terminología, la particularidad de este objeto radica en su escasa presencia dentro del registro arqueológico a lo largo del Imperio. Ciñéndonos a la ciudad de Augusta Emerita, constituye un unicum, no así para Hispania donde tenemos al menos otros cuatro ejemplos que, no obstante, difieren tanto en su cronología como en su morfología.

Son pocos los estudios que se han dedicado a estos objetos, obviamente en consonancia con la escasez misma de su presencia en los diversos contextos materiales. No obstante, hay varias publicaciones que han tratado de establecer tipologías, cronologías y usos para las huchas (salvadanai, tirelires, spardose o money-box), de las que destacamos, por

5 Alcancía: del ár. hisp. *alkanzíyya, este del ár. clás. kanz 'tesoro' y este del pelvi ganj. 1. f. vasija, comúnmente de barro, cerrada, con solo una hendidura estrecha hacia la parte superior, por donde se echan monedas que no se pueden sacar sino rompiendo la vasija.

Zephyrus, LXXVIII, julio-diciembre 2016, 131-150 
ser la primera en establecer una clasificación, el estudio de Graeven (1901: 160-189).

Este autor establece una primera tipología que refiere la existencia de huchas en forma de lucerna, templete, arca, olla, panal de abeja..., formas que posteriormente fueron simplificadas por Robinson (1924: 239-250) en cuatro grupos:

- En forma de arca, rectangulares y provistas de ranura de inserción en su cara superior.

- En forma de olla redondeada más o menos libremente por el alfarero, provista de ranura en la parte superior.

- Objeto circular que recuerda el depósito de una lucerna, generalmente decorado en su cara superior, donde se sitúa la ranura.

- Objeto cerámico en forma de panel de abeja, templo o santuario circular, generalmente decorado y con la ranura en uno de sus lados.

Esta misma clasificación sirve de base para el reciente estudio llevado a cabo por Baratta (2012:

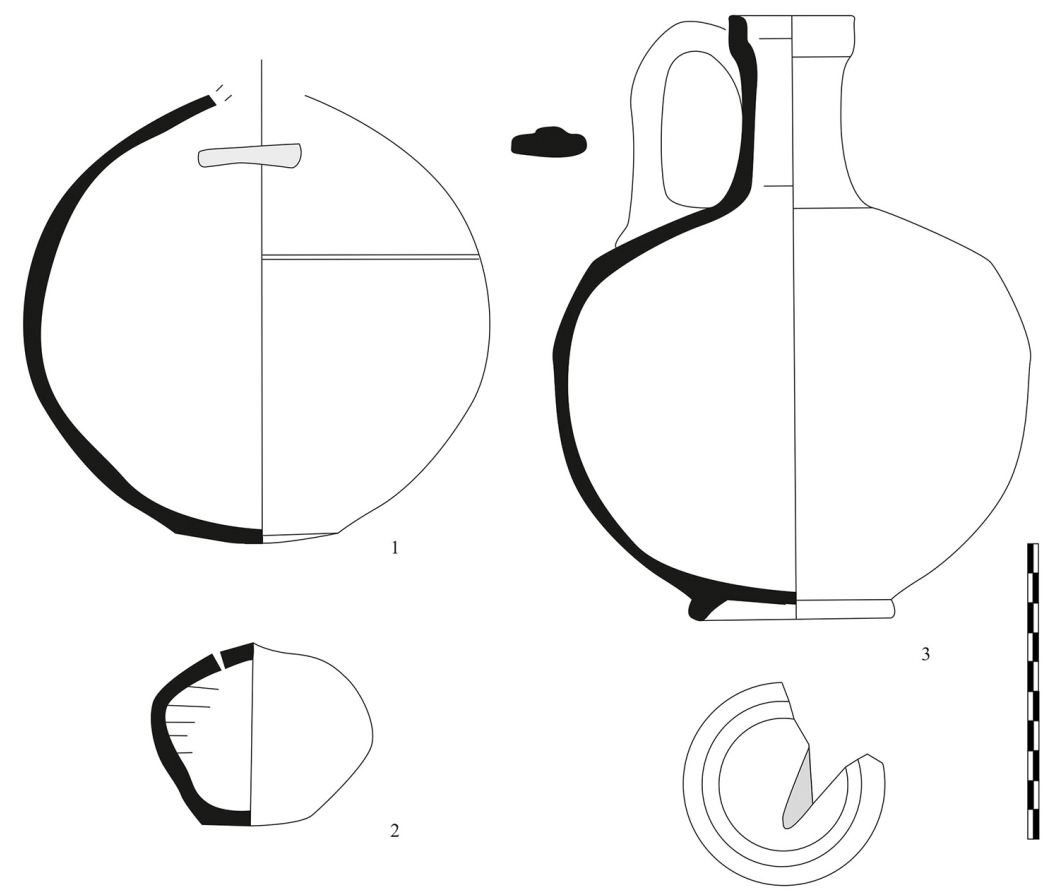

Fig. 9. Huchas localizadas en la Peninsula Ibérica: 1) Iluro; 2) Puig de Molins; 3) Lorca (dibujos a partir de VV. AA., 2003; Costa et al., 2004; Martínezy Ponce, 1999).
169-193), que amplía a cinco los tipos existentes en base a las formas y modos de elaboración. Así, a las huchas a pressa superiore u olla (Baratta, 2012: 171, fig. 2), paneles de abeja o a capanna (Baratta, 2012: 171-173, fig. 3), lucernas (Baratta, 2012: 173-174, fig. 4) o tipo arca (2012: 175-176, fig. 5), le añade la hucha a bicchiere (Baratta, 2012: 171, fig. 1).

Independientemente de estas clasificaciones, más o menos generales, la hucha de nuestra intervención corresponde al tipo II de Graeven, catalogada repetidamente tanto por unos como por otros bajo el nombre de olla (Robinson, 1924: 240-241, fig. 2) o "a pressa superiore" (Baratta, 2012: 171, fig. 2). Esta hucha es la forma más sencilla, elaborada a torno y la que ha perdurado casi invariable a lo largo del tiempo, tal y como atestiguan los ejemplos que abundan entre los materiales cerámicos de localidades como la extremeña Salvatierra de los Barros.

Como ya hemos indicado, de la Península proceden escasos contenedores publicados, huchas que se han localizado en áreas tan distantes como Ibiza, Murcia, Mataró o Cádiz (Fig. 9).

La primera de ellas formaba parte de un depósito material localizado en la necrópolis púnica de Puig de Molins (Fig. 9, n. 2). Esta alcancía, completa, era parte del material obtenido durante la documentación de la sepultura n. ${ }^{\circ} 10$, que, junto a un jarro de asa y un cuenco hondo, se ubicaron al noreste del enterramiento (Costas et al., 2004: 211-220).

La hucha corresponde a un recipiente de forma globular en cerámica común, con base plana e irregular y estrías en espiral en su fondo externo. En su parte superior posee una pequeña protuberancia o botón y junto a este una ranura rectilínea. Sus dimensiones son: 7,2 cm de altura, diámetro máximo de $8,5 \mathrm{~cm}$, diámetro de la base de 4,2 $\mathrm{cm} \mathrm{y}$ 
ranura de 2,4 cm de longitud (Costa et al., 2004: 218-219, fig. 5; lám. I, 3). En el interior de la misma, una vez vaciada la tierra que contenía, se localizaron dos monedas que, junto al estudio material, fechan el conjunto en un momento final del s. II o inicios del s. I a. C. En este artículo se rastrean otros ejemplares de época púnica, caso de los de Nora-Cerdeña (Pesce, 1961: fig. 118) o Lilibeo-Sicilia (Bisi, 1967: 689-690), las cuales aparecen en contexto funerario, hecho que lleva a pensar en prácticas rituales. Un análisis morfológico de los recipientes más antiguos induce a pensar en un aumento del tamaño a medida que se avanza el tiempo.

El segundo ejemplar se halló en las excavaciones llevadas a cabo en la ciudad de Lorca, concretamente en la c/ Eugenio Úbeda, lugar en el que se localizaron tres estancias interpretadas como parte de una instalación industrial (Fig. 9, n. ${ }^{\circ}$ 3). Amortizado en el s. III d. C. y, entre los materiales de relleno procedentes de una alfarería y de una industria de vidrio, se localizó una jarra provista de orificio que pronto fue identificada como una hucha (Martínez y Ponce, 1999: 317-319, fig. 19). Se trata de una jarra monoansada $-4,5 \mathrm{~cm}$ de diámetro y altura de 20,5 cm-, en la cual se había practicado en el momento de su manufactura una ranura en su base, lugar por donde insertar las monedas. Solo se ha hallado en su interior un sestercio que presentaba en su reverso la CONCORDIA AVGVSTA y que se localizó encajado en el cuello de la jarra (Martínez, 2003: 164-165).

La tercera se encuentra en la exposición permanente del Museo de Mataró, hallada durante los trabajos de excavación de una vivienda sita en la c/ de $\mathrm{Na}$ Pau en la antigua ciudad de Iluro (Fig. 9, n. ${ }^{\circ}$ 1). En esta ocasión, se presenta a modo de objeto globular con base cóncava y realizada en cerámica gris ibérica (vv. AA., 2003). El ejemplar se encuentra fragmentado, por lo que no se puede precisar cómo sería la parte superior del recipiente. El interés de la misma, además de por ser uno de los únicos ejemplares localizados en Hispania, radica en la precisa cronología que se puede aportar, concretamente en los niveles fundacionales de la Iluro republicana - c. 80-70 a. C. $-^{6}$.

6 Agradecemos los datos aportados por el Museo de Mataró.

(C) Universidad de Salamanca
Finalmente, la cuarta registrada se localiza en la colección permanente del Museo Arqueológico de Cádiz, procedente de las excavaciones efectuadas en 1989 en la Avda. Andalucía n. ${ }^{\text {os }}$ 8-10 (Fig. 10). En esta intervención se pudieron documentar los restos de un taller alfarero datado en el s. II d. C., que cohabitó con un espacio funerario (Lara et al., 2015: 28-35). Esta hucha es un objeto completo de forma globular y culminada con una especie de mamelón redondeado. En el tercio superior de la pieza presentaría una ranura perpendicular al eje de la misma que permitiría la inserción de las monedas en su interior. El hecho de que la rotura ha sido hecha precocción habla de un plan previo a la realización de la pieza.

Como vemos, hasta ahora son cuatro las huchas documentadas en la Península Ibérica, a las que hay que sumar la localizada en nuestra intervención, un exiguo número de piezas en relación a los materiales cerámicos que se pueden localizar en cualquier yacimiento. Esta escasez de objetos en los registros materiales no debemos asociarla con un carácter excepcional dentro del repertorio tipológico cerámico, sino más bien con cuestiones más ordinarias,

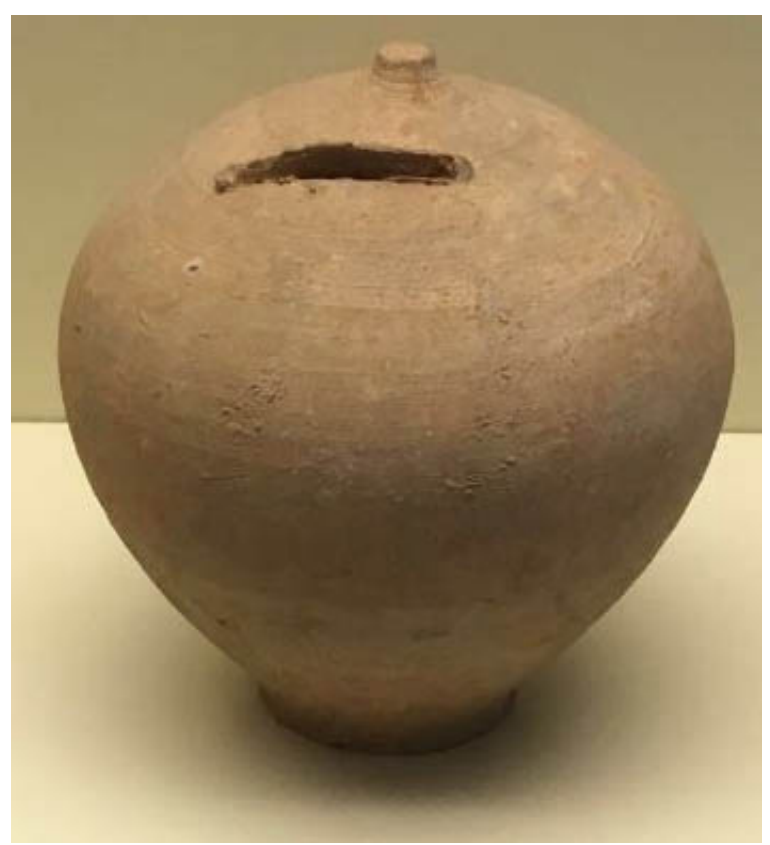

Fig. 10. Hucha localizada en Cádiz (fotografía del Museo de Cádiz). 
tales como su propia utilidad. Como recipiente destinado al ahorro, para poder acceder a su contenido se precisaba su rotura, por lo que, tal y como ya hacen notar algunos autores (Longpérier, 1869: 168; Chinchilla, 1992: 261; Baratta, 2012: 177), salvo aquellas piezas completas, las fracturadas son de difícil identificación dentro de los múltiples fragmentos que se pueden inventariar en cualquier intervención arqueológica, máxime si estos acababan en los tradicionales vertederos.

Distinto caso es su identificación en los talleres artesanales de producción, tal y como se han podido documentar para las piezas etruscas de Chiusi (Pucci y Mascione, 2003: 218-219). Sin embargo, no es el caso de ninguna de nuestras huchas, salvo la alcancía de Cádiz, siempre que consideremos este objeto como parte del repertorio tipológico de los hornos y no un objeto de depósito funerario de alguna de las tumbas. Para Augusta Emerita, hasta la fecha, a pesar de ser numerosos los contextos materiales analizados procedentes de los talleres cerámicos, no se han podido reconocer objetos semejantes dentro de sus repertorios productivos (Alvarado y Molano, 1995; Alba y Méndez, 2005; Bustamante, 2011).

En relación a la utilidad de estos contenedores, los estudios que se han venido realizando para estas piezas, en cualquiera de sus modalidades, adolecen de la misma imprecisión a la hora de determinar para qué eran empleadas.

Si bien por su forma debieran estar destinadas a acoger dinero como medio de ahorro, sin embargo, es muy escaso el hallazgo de ejemplares completos que presentan monedas en su interior, salvo contadas excepciones como la alcancía de Murcia; el contenedor de Lincoln con monedas de Constantino el Grande -similar al de Mérida- (White, 1981: 302-305)7; el hallado en North Wiltshire con una serie de denarios, interpretados como regalo (Robinson, 1924: 241), o la hucha de las Termas de Tito, decorada con tres divinidades y con 251

7 En la ficha de catalogación del British Museum la pieza aparece descrita como "Pottery money-box. Globular with flat base and bell top, slit at top. Dark grey ware. Contained coins (described as denarii but actually fourth century nummi) when found". denarios en su interior, que abarcan desde época republicana hasta el emperador Trajano (Daremberg-Saglio, 1904). También expuesta en el British Museum y procedente de Cherchel (Argelia), se encuentra una hucha de escasas dimensiones y muy cercana al ejemplar emeritense que centra nuestro trabajo -datos recogidos por Costa et al. (1999: n. 11)-. De perfil también cercano al localizado en Mérida aunque de tendencia más estilizada serían dos ejemplares localizados en la antigua Byzacena -concretamente en Cartago y Chemtou- y recogidos en la tipología de Bonifay (2004: fig. 168, tipo 73 , n. $\left.{ }^{\text {s }} 1-3\right)$. En ambos se repite su perfil a modo de olla culminado con un pequeño pedúnculo que no tendría función específica debido a sus reducidas dimensiones. Sin embargo, otro de los ejemplares recogidos por este autor y procedente de Oudhna sí presentaría un mamelón superior más historiado y claramente destinado a usarse como asidero de la pieza (Bonifay, 2004: fig. 168, tipo 73, n.o 2). Un ejemplar de interés por su acabado polícromo sería una jarra monoansada policromada procedente de Herculano (Fig. 11).

Hemos de pensar que la funcionalidad de estas piezas como depositarias de ahorros estaría ligada

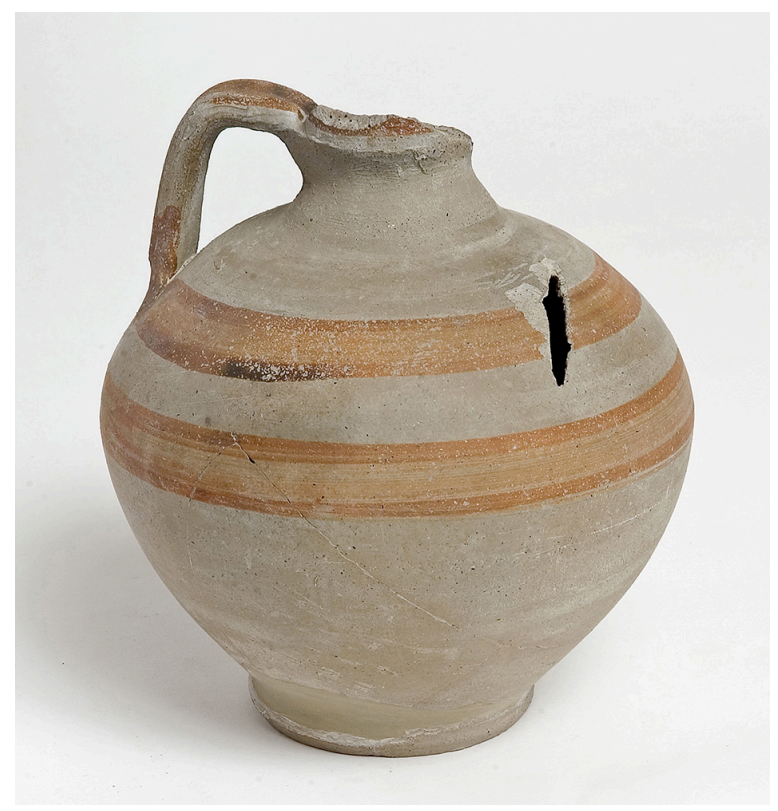

FIG. 11. Hucha sobre jarra localizada en Herculano (fotografia del SAP). 
a aquellos objetos similares que se han conservado fragmentados, rotura intencionada para extraer las monedas de su interior (Fiedler y Höpken, 2007b: 96-97).

No obstante, existen otras interpretaciones ofrecidas para estos objetos que se centran básicamente en los motivos decorativos, las formas o los sellos usados en ellos como ornamentación.

Por sus especiales características, son las huchas de 'panel de abeja' las que más han focalizado las investigaciones, no solo en relación con su forma que, para algunos (Robinson, 1924: 248-249), recuerda a las representaciones de omphaloi en las tumbas micénicas sino por sus elementos decorativos y sellos. Así, la presencia de templos en los que se incluyen las figuras de dioses, preferentemente Mercurio y Fortuna, vinculados con el comercio, la fortuna y la abundancia, se ha querido ver como un deseo de prosperidad para el propietario del recipiente (Baratta, 2012: 178). Estas vasijas, a las que sumamos aquellas en forma de arca, algunas veces decoradas y que son exclusivamente pompeyanas, se estudian en relación con los lararios, cajas que se ubicaban en los atrios de las mejores domus ornamentadas con pequeñas figuras, generalmente de bronce, a las que se dan interpretaciones diversas como ofrendas de fortuna o bienestar, valor censal o lugar donde guardar el tesoro familiar (Graeven, 1901: 168, figs. 6-7; Cheilik, 1963: 70-71, pl. 16; Pérez Ruiz, 2012: 292-294, fig. 9).

Otros estudios se focalizan en las huchas en forma de lucernas y su significado, en este caso, ligado con los obsequios y regalos entregados a los niños en el año nuevo, en el marco de las saturnalia. Esta idea se apoya básicamente en aquellas piezas que presentan en su disco la figura de una Victoria alada sosteniendo un clipeus con la leyenda ANNVM NOVVM FVSTVM FELICEM MIHI • HIC (Ficoroni, 1745: 102-103; Walters, 1901: 398-389, 420-421).

Sin embargo, para las formas más simples, ya sean las huchas a bicchiere (Baratta, 2012: 171, fig. 1) o en forma de olla, como la que nos ocupa, la falta de indicadores, como una decoración, un graffiti o marcas de alfarero, dificulta determinar su funcionalidad. A esta carencia de información directa

(C) Universidad de Salamanca obtenida de la pieza, se suma la ausencia, en gran parte de los casos analizados, de monedas en su interior.

Atendiendo a la localización de los objetos, se podría formular una serie de propuestas destinadas a aclarar la funcionalidad de los mismos. Así, en enclaves como Apulum, se registraron varias fragmentadas, ninguna de ellas con monedas en su interior, ubicadas en fosas/favissae cultuales practicadas en el templo de Liber Pater (Fielder, 2005: 95-125). Estas huchas, las de mayor tamaño, aparecían rotas para poder conseguir el dinero de su interior, siendo a posteriori depositadas en estas fosas. La obtención del capital ahorrado se ha puesto en relación con una financiación privada del sepelio, en la que las huchas serían los objetos destinados a recaudar los fondos necesarios para tal culto.

Distintas son las 15 huchas en miniatura halladas en estos pozos, realizadas ex profeso por los artesanos, con ranuras de pequeño tamaño que imposibilitarían su uso como receptáculo de monedas. En estos casos se les asigna directamente un carácter ritual como ofrendas similares a otros objetos en miniatura (Fiedler y Höpken, 2007a: 440-441, Abb. 7).

Quizás una de las áreas que más ejemplares nos aporta es Alemania. En Trier se ha documentado en las termas un ejemplar globular con ranura en su cara superior (Hussong y Cüppers, 1972: taff. $7,58)$. En Colonia, por el contrario, se halló un conjunto de huchas que se relacionan con las áreas funerarias, formando parte de los depósitos materiales. Estas huchas aparecían vacías y generalmente fragmentadas en su parte superior. Solamente una de ellas, una inhumación procedente de una de las tumbas de la c/ Luxemburgo, tenía a sus pies la hucha fragmentada y monedas, un total de 22 , que se localizaron en la cabecera, todo ello junto a un rico depósito material.

Estos hallazgos llevan a estudiar la presencia de estas huchas en el interior de las sepulturas bajo diversas ópticas. En primer lugar, su aparición en estos contextos funerarios se interpreta como piezas asociadas a los depósitos funerarios, estando consideradas objetos inútiles y carentes de la función para la que se realizaron ya que estaban fracturadas (¿para sacar el dinero?), o bien presentaban errores

Zephyrus, LXXVIII, julio-diciembre 2016, 131-150 
de cocción. La segunda teoría puesta de manifiesto determina la presencia de las alcancías como símbolo del dinero recogido por amigos y/o parientes, o bien los collegia funerarios, capital asignado para el funeral, ahorrado y gastado con ocasión del sepelio (Höpken, 2008: 56-58).

Finalmente, hay otras huchas, las menos, que se localizan en espacios bien domésticos o industriales, como la hucha de Wiesloch en un contexto de figlinae. En esta ocasión se presenta con una forma cilíndrica y una superficie muy alisada (Hensen, 1998: fig. 2, n. ${ }^{\circ}$ 1). En estos casos su uso sería el propio de este objeto, empleado como contenedor de ahorros o pagos (Höpken, 2008: 56-58).

En época medieval y moderna la aparición de estos recipientes es fruto de una práctica común en contextos de crisis y debilidad económica. La tipología en dichos momentos se multiplica apareciendo tanto recipientes polivalentes (Hortelano y Gozalbes, 2005) como piezas realizadas ex profeso (Ayerbe, 2015: 322, fig. 31).

\section{Conclusiones}

Con esta aportación hemos querido analizar una tumba cuyo interés radica tanto en su contexto de aparición -una zona de amplia tradición funeraria- como por el depósito localizado en su interior. Aunque el ritual usado, la incineración, impide determinar con precisión el sexo del difunto, sí parece posible deducir que se trata de un sujeto adulto y, sobre todo, a partir de las piezas que lo acompañan que fuera de sexo femenino. De todos los objetos que componían el ajuar, hemos centrado nuestro interés, por su escasez en los contextos hispanos, en una hucha gestada ex profeso para este fin. El hecho de que esta pieza haya sido recuperada en contexto nos ha permitido proponer una datación fiable para la misma, ya que los estudios desarrollados hasta la fecha para otras similares no han podido concretar su cronología.

La hucha analizada procede de un contexto funerario y parece estar ligada a un enterramiento femenino que, por el tipo de ajuar que se le asocia, se

(C) Universidad de Salamanca fecha a fines del s. I d. C. Este recipiente se presenta en óptimo estado de conservación, sin mostrar errores en su proceso de manufactura ni tampoco fracturas postdeposicionales. Sin embargo, como hemos indicado, aparecía vacía de contenido. Así, a la hora de esclarecer su presencia entre los materiales que acompañaron a la difunta, no podemos presuponer, tal y como se recoge en los ejemplos anteriores, como la alcancía donde se habrían contenido los ahorros destinados al pago de los fastos del funeral -ya que se habría necesitado obliterar dicho recipiente para recuperarlos-.

En este sentido, pensamos que su presencia, junto a los otros materiales, obedece a cuestiones de carácter simbólico relacionadas con el rito propio del enterramiento en las fechas que nos ocupan.

Como pieza que configura el depósito material, entendemos que se trataría de un objeto asignado por los familiares para que acompańara a la difunta en su tránsito al Más Allá. En este sentido, a los elementos de adorno - acus crinales y broches- y el restante depósito material, se sumarían la hucha y la moneda. Tipológicamente no hemos encontrado ningún paralelo exacto ni en suelo emeritense ni en todo el Imperio que permita suponer una producción seriada. Más bien parece que estamos ante el capricho puntual de un alfarero de una ciudad muy presta a las innovaciones en la producción cerámica.

Sin embargo, del análisis de las otras piezas diseminadas en el Imperio sacamos de conclusión que sí existió un concepto tipológico homogéneo tal y como vemos en la similitud de las piezas localizadas en otros puntos del Imperio donde su perfil globular y el mamelón superior son elementos constantes.

En un intento de interpretar la presencia de la hucha en esta sepultura, creemos que no debemos individualizar el objeto, sino analizarlo en conjunto con la "moneda de la difunta" (Grinder-Hansen, 1991: 207-218), al estar la alcancía expresamente colocada sobre la misma.

Así, la moneda, que aparece calcinada, inicialmente estaría acompañando a la fallecida en el sepelio y durante la cremación, adquiriendo de este modo el tradicional significado de pago para el barquero Caronte. Posteriormente, recogidas las

Zephyrus, LXXVIII, julio-diciembre 2016, 131-150 
cenizas y carbones, purificada la fosa y colocados los depósitos materiales secundarios, la moneda se coloca intencionadamente en relación indirecta con la alcancía ${ }^{8}$, momento en el cual pasa a adquirir otro sentido, que la vincularían a nivel conceptual con la hucha (Vaquerizo, 2011: 104-105, nota 32).

En este sentido, hemos de hacer un repaso a los estudios que se han venido realizando sobre la presencia de las monedas en los contextos funerarios, y que establecen no solo la tradicional interpretación como medio de pago al barquero Caronte para el tránsito al más allá, sino que se les asignan otros significados, algunos condicionados a su disposición dentro de la tumba en relación con el cadáver (Angeli, 2007: 51-52). Así, la moneda está considerada como un distintivo del estatus social del difunto, un amuleto o talismán, o simplemente forma parte de las joyas que acompañaban al finado (Facchinetti, 2013: 22-33; Cantilena, 1995: 165-177; Ceci, 2001: 90-91; Grinder-Hansen, 1991: 210-211).

Centrándonos en su significado como amuleto o talismán, la moneda adquiere un carácter de objeto protector y como talismán es un objeto destinado a ejercer una influencia positiva (Pera, 1993: 347). Recientes estudios han analizado el valor de la moneda como objeto protector o símbolo de buen augurio, sentido que se transmite no solo a las piezas monetales localizadas en las tumbas, sino a aquellas que han aparecido vinculadas a construcciones tanto de ámbito público como privado (Facchinetti, 2012: 337-351).

Ligada a su presencia en los enterramientos, es su forma redondeada y el metal en el que se fabrica lo que le aporta un significado como talismán contra los elementos adversos, al que se le suma un carácter mágico como objeto de buen augurio (Perassi, 2011: 228-229).

Atendiendo a estas interpretaciones, podemos intentar establecer un valor a ambos elementos dentro de la tumba de nuestra difunta. Así, cumplido su cometido primigenio como moneda destinada al pago a Caronte -por ello se colocó como parte del

8 Aunque hucha y moneda están ocupando un mismo espacio no presentan relación directa; recordemos que su tamaño es superior a la ranura. depósito primario-, en su ubicación definitiva, bajo la hucha, adquiriría una significación no sabemos si distinta y/o complementaria con la precedente, que la entroncaría indirectamente con la hucha, en su calidad de posible strenae (Pera, 1993: 353-354), definiendo ambos objetos como muestra material del deseo de familiares de buena fortuna y deseo de prosperidad en la otra vida.

En cualquier caso, y dado que nos movemos dentro del mundo ritual y conceptual, esta posibilidad planteada no deja de ser una hipótesis más de trabajo, planteamiento que sumar a cualquier otra posible interpretación. En esta línea, esperamos que nuevos hallazgos nos puedan esclarecer algo más en torno al uso y significado de las huchas en el mundo romano.

\section{Bibliografía}

Abascal, J. M. (1991): "La muerte en Roma: fuentes, legislación y evidencia arqueológica". En VAQUERIzo, D. (coord.): Arqueología de la muerte. Metodología y perspectivas actuales. Córdoba, pp. 205-245.

Alba, M. (2005): "Dos áreas funerarias superpuestas, pagana e islámica, en la zona sur de Mérida. Intervención arqueológica realizada en un solar en la confluencia de la calle Albuhera y avenida de Lusitania", Mérida. Excavaciones Arqueológicas 2002, 8, pp. 309-342.

AlBA, M. (2011): "Las áreas funerarias paleoislámicas de Mérida". En Actas I-II Jornadas de Arqueología e Historia Medieval en La Marca Inferior de Al-Andalus. Mérida, pp. 13-56.

Alba, M. y Méndez, G. (2005): "Evidencias de industria paleolítica y de un alfar altoimperial en Augusta Emerita. Intervención arqueológica realizada en el solar de esquina entre la prolongación de la calle Anas y el final de la avenida de Lusitania", Mérida. Excavaciones Arqueológicas 2002, 8, pp. 375-409.

Alvarado, M. y Molano, J. (1995): “Aportaciones al conocimiento de las cerámicas comunes altoimperiales en Augusta Emerita: el vertedero de la c/ Constantino". Monografias Emporitanes, VIII, pp. 281-295.

Angeli, G. (2007): "Reperti monetali dalla necropoli di vía Bengasi”. En JaiA, A. M. (coord.): Capolavori Ritrovati dal Museo Nazionale Romano. Quaderni del Museo Civico Archeologico di Anzio, n. ${ }^{\circ} 3$, pp. 49-57.

Zephyrus, LXXVIII, julio-diciembre 2016, 131-150 
Ayerbe, R. (2015): “Evolución diacrónica de un espacio intramuros en el urbanismo de Augusta Emerita. Intervención arqueológica realizada en el solar n. ${ }^{\text {o }}$ 4-6 de la cl Arquitas (Mérida)", Mérida. Excavaciones Arqueológicas 2005, 11, pp. 293-326.

Baratta, G. (2012): "De brevissimis loculis patrimonium grande profertur (Tert. cult. fem. 1, 91, 19): i salvadanai", Sylloge Epigraphica Barcinonensis, x, pp. 169-193.

Bejarano, A. M.a (2002): "Nuevos datos acerca del área funeraria de época altoimperial ubicada en el antiguo solar de la Campsa. Intervención arqueológica realizada en el solar de la antigua Campsa s/n", Mérida. Excavaciones Arqueológicas 2000, 6, pp. 217-240.

Bejarano, A. M. a (2015): La medicina en la Colonia Augusta Emerita. Serie Ataecina, 9. Mérida.

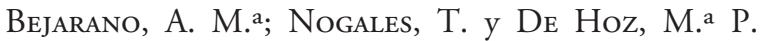
(2015): "Nueva placa-relieve femenina en Augusta Emerita: Identidad e iconografía de Lampas", Anas, 23, pp. 189-210.

Bisı, A. M. (1967): "Lilibeo (Marsala). Nuovi scavi nella necropoli punica (1969-1970)", Atti della Accademia Nazionale dei Lincei. Notizie degli scavi di Antichità, XXV, pp. 662-762.

Bonifay, M. (2004): Études sur la céramique romaine tardive d'Afrique. BAR Series, 1301. Oxford: Archaeopress Open Access 2015.

Bustamante, M. (2011): La cerámica romana en Augusta Emerita en época altoimperial. Entre el consumo y la exportación. Serie Ataecina, 7. Mérida.

Bustamante, M. (2014): "Nuevas consideraciones cronológicas de la forma XuIII en paredes finas emeritenses”. En Centro y periferia en el mundo clásico. Actes XVIII CIAC. Mérida, pp. 1467-1469.

Cariño, M. y Montefore, M. (2007): “De la sobreexplotación a la sustentabilidad: Nácar y perlas en la historia mundial”, El Periplo Sustentable, 12, pp. 81-131.

Cantilena, R. (1995): “Un obolo per Caronte?". En Caronte Un obolo per l'aldilà, La Parola del Pasato, 50 (III-VI), pp. 165-177.

Ceci, F. (2001): "L'interpretazione di monete e chiodi in contesti funerari: esempi dal suburbio romano". En Culto dei morti e costumi funerari romani, Atti Colloquio Internacional (Roma, 1988). Roma, pp. 87-97.

Chamizo, J. J. (2006): "La Vía de la Plata: nuevos datos sobre la salida norte de Augusta Emerita. Intervención arqueológica en el solar sito en la esquina Avda. Vía de la Plata con C/ Albañiles", Mérida. Excavaciones Arqueológicas 2003, 9, pp. 15-35.
Cheilik, S. M. (1963): "A Roman Terracotta Saving-Bank", American Journal of Archaeology, 67, pp. 70-71.

Chinchilla, M. (1992): "Alcancías hispano-árabes en el MAN". En Jarique de Numismática Hispano-Arabe (Madrid, 1990). Madrid: MAN, pp. 259-268.

Costa, B.; Fernández, J. H. y Mezquida, A. (2004): "Ahorros para la otra vida una sepultura púnica conteniendo una hucha en la necrópolis del Puig des Molins (Eivissa) y su contexto histórico”. En Matilla, G.; Egea, A. y González Blanco, A. (coords.): El mundo púnico: religión, antropología y cultura material. Actas II Congreso Internacional del Mundo Púnico (Cartagena, 2000). Murcia, pp. 207-242.

Daremberg, Ch. V. y Saglio, E. (1904): Dictionnaire des antiquités grecques et romaines, d'après les textes et les monuments. Paris, t. III/2, pp. 1292-1295.

Facchinetti, G. (2012): "Ritualità Connesse alla Costruzione di Domus. Le Offerte Monetali di Fondazione ad Aquileia”. En Bonetto, J. y Salvadori, M. (coords.): L'architettura privata ad Aquileia in età romana. Atti Convegno di Studio (Padova, 2011). Padova, pp. 337-352.

FacchinetTi, G. (2013): "Quando la moneta parla all'archeologo: monete da contesti Archeologici”. En Facchinetti, G. y Pennestrì, G. (eds.): L'eredità salvata. Istituzioni, collezioni, materiali a Milano tra numismatica ed archeologia. Mostra all'Antiquarium "Alda Levi" (Milán, 2013). Notiziario del Portale Numismatico dello Stato, Ministero dei Beni e delle Attività Culturali e del Turismo Direzione Generale per le Antichità, n. ${ }^{\circ} 3$, pp. 22-33.

FICORONI, F. (1745): Le memorie ritrovate nel territorio di Labico e i loro giusti siti. Roma.

Fiedler, M. (2005): "Kultgruben eines Liber Pater-Heiligtums im römischen Apulum (Dakien) -ein Vorbericht”, Germania, 83, pp. 95-125.

Fiedler, M. y Höpken, C. (2007a): "Das 'gemeinschaftliche' und das 'private' Opfer: Beispiele aus dem Spektrum von Votivpraktiken in römischen Heiligtümern, dargestellt an Befunden aus Apulum und Sarmizegetusa (Dakien)". En Frevel, Ch. y HesBerg, H. (eds.): Kult und Kommunikattion. Medien in Heiligtümern der Antike. Wiesbaden: Verlag, pp. 435-466.

Fiedler, M. y Höpken, C. (2007b): "Spardosen und Miniatur-Spardosen - Neufunde aus dem römischen Apulum (Rumänien)". En Keramik auf Sonderwegen. Außergewöhnliche Formen und Funktionen 37 (Internationales Hafnerei-Symposium. Herne 19, bis 25.9,

Zephyrus, LXXVIII, julio-diciembre 2016, 131-150 
2004). Denkmalpflege und Forschung in Westfalen, 44, pp. 95-99.

Graeven, H. (1901): "Die thonerne Sparbüchse im Altertum", Jahrbuch des Kaiserlichen Deutschen Archáologischen Instituis, 16, pp. 160-189.

Grinder-Hansen, K. (1991): "Charon's fee in Ancient Greece? Some remarks on a Well-Known Death Rite”, Acta Hyperborea, III, pp. 207-218.

Hensen, A. (1998): "Eine römische Sparbüchse aus Wiesloch", Archäologische Nachrichten aus Baden, 59, pp. 3-6.

Höpken, C. (2008): "Römische Spardosen aus Köln". En Kölner Museums-Bulletin. Berichte und Forschungen aus den Museen der Stadt Köln, 2, pp. 54-80.

Hortelano, I. y Gozalbes, M. (2005): "Una hucha casi vacía procedente de Manises”. En Ribera, A. y Ripollés, P. P.: Tesoros Monetales de Valencia y su entorno. Valencia, pp. 293-299.

Hussong, L. y Cüppers, H. (1972): Die Trierer Kaiserthermen. Die spátromische und frühmittelalterliche Keramik. Trierer Grabungen und Forschungen, I/2. Mainz.

Isings, C. (1957): Roman Glass From Dated Finds. Groningen.

Lara M.; Díaz, J. J. y Bernal, D. (2015): "Excavando en los archivos. Novedades sobre la alfarería romana en Gades a partir de la documentación arqueológica del solar de la Avda. Andalucía 8-10", Boletín de la SECAH, 6, pp. 28-35.

LE Ny, F. (1988): Les fours de tuliers Galo-romains. Méthodologie, étude technologique, typologique et statistique. Chronologie. DAM, 12. Paris.

LONGPÉrier, H. DE (1869): "Recherches sur les récipients monétaires", Revue Archéologique, 19, pp. 163-171.

Márquez, J. (2005): "Excavación de una de las áreas funerarias al sur de la ciudad, desde la segunda mitad del s. I d. C. hasta época andalusí: una maqbara al sur de Marida. Intervención arqueológica realizada en un solar de la C/ Leonor de Austria s/n (Mérida)", Mérida. Excavaciones Arqueológicas 2002, 8, 281-308.

MárqueZ, J. (2008): "Las áreas funerarias de Augusta Emerita entre los siglos I y iII d.C.”. En Mangas, J. y ÁNgel, M. (eds.): El Territorio de las Ciudades Romanas. Madrid: edic. Sísifo, pp. 443-476.

Márquez, J. y Pérez Maestro, C. (2005): “El primer puticuli documentado en Augusta Emerita: contextualización topográfica y cronológica", Mérida. Excavaciones Arqueológicas 2002, 8, pp. 533-545.
Martínez Mira, I. (2003): "Hucha cerámica del s. III d.C. del Museo Arqueológico Municipal de Lorca (Murcia)", Lucentum, xx-xxII, pp. 2002-2003.

Martínez Rodríguez, M. y Ponce, J. (1999): “Excavaciones arqueológicas de urgencia en la Calle Eugenio Úbeda, 12-14 (Lorca, Murcia)". En Actas Quintas Jornadas de Arqueología Regional (1994). Memorias de Arqueología, 8. Lorca, pp. 298-329.

Mayet, F. (1975): Les cerâmiques a Parois Fines dans la Peninsule Ibérique. Paris.

Méndez, G. (2006): "Origen, desarrollo y cambios funcionales producidos en un solar extramuros de la ciudad desde el s. I d. C. hasta el v d. C. Intervención arqueológica realizada en un solar situado entre las calles José Echegaray, Barcelona y Avda. de Lusitania (Mérida)", Mérida. Excavaciones Arqueológicas 2003, 9, pp. 357-382.

Méndez, G. y Alba, M. (2004): “Un conjunto de hornos cerámicos romanos situados junto al río Ana. Intervención arqueológica realizada en un solar de la Avda. de Lusitania, esquina con la C/ Dámaso Alonso (1. a Fase)", Mérida. Excavaciones Arqueológicas 2001, 7, pp. 307-332.

Molano, J. y Alvarado, M. (1994): "La evolución del ritual funerario de Augusta Emerita como indicador del cambio social, ideológico y religioso". En Actas I Congreso de Arqueología Peninsular. Trabalhos de Antropologia e Etnologia. Porto, pp. 321-350.

Nodar, R. (2001): "Restos de la pars urbana de una villa situada al Sur de Emerita Augusta. Intervención arqueológica realizada en el solar sito en la Ctra. de D. Álvaro, antigua fábrica de El Águila", Mérida. Excavaciones Arqueológicas 1999, 5, pp. 267-283.

Pera R. (1993): "La moneta antica come talismano". En Moneta e non moneta. Atti del convegno internazionale di studi numismatici in occasione del centenario della Società numismatica italiana (1892-1992) (Milano, Palazzo delle Stelline, 1992). Rivista italiana di numismatica e scienze affini, 95. Milán, pp. 347-361.

Perassi, C. (2011): "Monete romane forate: qualche riflessione su 'un grand théme européen' (J.-P. Callu)", Aevum, 85 (2), pp. 257-315.

Pérez González, J. (2014): "Los Margaritarii: comerciantes de lujo”. En Álvarez Martínez, J. M.; Nogales, T. y RodÁ, I. (eds.): Centro y periferia en el mundo clásico (Actas XVIII CIAC). Mérida, vol. 2, pp. 1413-1415.

Pérez Ruiz, M. (2012): “Aproximación a la cultura material asociada al culto doméstico en el mundo romano. Surveying the material culture related to the 
150 A. M. Bejarano y M. Bustamante / Huchas cerámicas de época romana. A propósito del hallazgo de una tumba...

domestic cult in the Roman world", Espacio, tiempo y forma, Serie i, Nueva época. Prehistoria y Arqueología, 4, pp. 285-308.

Pesce, G. (1961): Sardegna punica. Cagliari.

Pucci, G. y Mascione, C. (2003): Manifattura ceramica etrusco-romana a Chiusi. Il complesso productivo di Marcianella. Bari.

Robinson, D. M. (1924): "Some roman terra-cotta savings-bank", American Journal of Archaeology, XXviII (3), pp. 239-250.

Rodríguez Hidalgo, A.; Gibello, V. M.; Menéndez, A.; Sanabria, D. y Sánchez Hidalgo, F. (2013): "Un ejemplar de Cypraea pantherina en una tumba altoimperial de Augusta Emerita", Zephyrus, 72, pp. 183-193.

Sánchez Barrero, P. D. (2010): Itinerarios y caminos romanos en el entorno emeritense. Serie Ataecina, 6. Mérida.

Scatozza, L. A. (1986): I vetri romani di Hercolano. Roma.

TAssini, P. (1994): "Produzione e vendita di alcune merci di lusso a Roma". En Epigrafia della Produzione e della distribuzione. Actes VIIe Rencontres franco-italienne sur l'épigraphie du monde romain (Roma, 1992). MEFRA, 193. Roma, pp. 687-695.

Thédenat, H. (1904): Loculus, loculi, locellus, loculamentum. En Daremberg, Ch. y SAglio, E.: Dictionnaire des antiquités grecques et romaines. Paris, t. III.

Vaquerizo, D. (2010): Necrópolis urbanas en Baetica. Serie Documenta, 15. Tarragona: ICAC-Univ. de Sevilla.

Vaquerizo, D. (2011): "De la agonía al luto. Muerte y funus en la Hispania romana”. En Pacheco, C. (coord.): La muerte en el tiempo. Arqueologia e historia del hecho funerario en la provincia de Toledo. Talavera de la Reina: Colectivo de Investigación Histórica Arrabal, pp. 95-125.

Walters, H. B. (1905): History of ancient pottery: Greek, Etruscan, and Roman. London, vol. 2.

White, A. J. (1981): "A Roman Pottery Money-Box from Lincoln”, Britannia, 12, pp. 302-305.

vv. AA. (2003): Fem arqueologia Descobrim la ciutat. Mataró: Ayto. de Mataró. 